\title{
Optimal energy saving in DC railway system with on-board energy storage system by using peak demand cutting strategy
}

\author{
Chaiyut Sumpavakup ${ }^{1} \cdot$ Tosaphol Ratniyomchai $^{1} \cdot$ Thanatchai Kulworawanichpong $^{1}$ (i)
}

Received: 4 July 2017/Revised: 27 September 2017 / Accepted: 7 October 2017/Published online: 22 October 2017

(c) The Author(s) 2017. This article is an open access publication

\begin{abstract}
A problem of peak power in DC-electrified railway systems is mainly caused by train power demand during acceleration. If this power is reduced, substation peak power will be significantly decreased. This paper presents a study on optimal energy saving in DC-electrified railway with on-board energy storage system (OBESS) by using peak demand cutting strategy under different trip time controls. The proposed strategy uses OBESS to store recovered braking energy and find an appropriated time to deliver the stored energy back to the power network in such a way that peak power of every substations is reduced. Bangkok Mass Transit System (BTS)-Silom Line in Thailand is used to test and verify the proposed strategy. The results show that substation peak power is reduced by $63.49 \%$ and net energy consumption is reduced by $15.56 \%$ using coasting and deceleration trip time control.
\end{abstract}

Keywords DC-electrified railway · Energy saving · On-board energy storage system .

Regenerative braking energy $\cdot$ Peak power reduction

Thanatchai Kulworawanichpong

thanatchai@gmail.com

Chaiyut Sumpavakup

nonny.ee@gmail.com

Tosaphol Ratniyomchai

tosaphol@sut.ac.th

1 School of Electrical Engineering, Suranaree University of Technology, Nakhon Ratchasima 30000, Thailand

\section{Introduction}

Recently, the demand for public transport has rapidly increased around the world. Many countries in Asia such as Thailand, Singapore and India have plans to expand the existing routes in their mass transit systems to cover all urban areas [1]. Energy efficiency and management are undoubtedly the big challenges in the railway systems [2]. In electric traction systems, recuperation of the braking energy highly improves energy efficiency [3, 4]. Depending on the driving cycle and control strategy, energy saving could be achieved by approximately $8 \%$ to as much as $25 \%$ of the total energy drawn by the vehicle [5]. An urban rail transit is characterized by many service stations with frequent acceleration and braking of trains that increases the potential of braking energy recuperation using energy storage system (ESS). There are two main applications of ESS in the electrified railway: (1) trackside energy storage system (TESS) and (2) on-board energy storage system (OBESS). With the OBESS, regenerated braking energy is stored in the OBESS when the line is not receptive and there is no adjacent train demanding high power. The stored energy will then be used to support train acceleration or within an appropriate condition. Gonzalez-Gil et al. [6] explains that the OBESS has higher efficiency than TESS and its energy management is simpler as there are no line losses and traffic conditions considerations.

In general, the purposes of the regenerative braking energy management with OBESS are increasing energy efficiency [7-9], reducing peak power of substations [10] and stabilizing network voltage [11, 12]. The research presented in this paper is devoted to reducing substation peak power mainly in DC metro systems. In Ref. [10], a $25 \%$ reduction of the overall railway electricity cost was achieved by reducing substation peak power during train 
acceleration. In Thailand, electricity tariff consists of 4 types of charges: energy charge (THB/kWh), demand charge $(\mathrm{THB} / \mathrm{kW})$, service charge (THB/month) and power factor charge (THB/kvar). The demand charge is defined as the maximum 15-minute integrated demand during on peak over the monthly billing period. Reducing peak power can significantly reduce the total monthly bill. With the OBESS, there are two parameters that affect energy saving: (1) the number of the OBESS modules, which has impact on the effective weight of the train and consequently energy consumption and (2) initial state of charge (SOC) of the OBESS, which has impact on the functional restrictions of the OBESS. Therefore, the problem has been tackled by finding the suitable parameters of the number of OBESS modules and the initial SOC for optimal energy saving. Several energy-saving strategies incorporating OBESS have been presented in the literature, each of which has some difficulties, such as the rule-based strategies (RBS) $[11,13]$, the strategy based on the SOC [14] and the control strategies based on fuzzy logic [15]. However, optimizing the starting point of OBESS discharge is difficult in realtime simulation.

This paper studies the optimal energy saving in DC metro systems using OBESS with peak demand cutting strategy. The aim is to evaluate how much an optimized set can maximize energy saving under different trip time controls. The operated design criteria of the OBESS, the strategy of the power flow controller and the trip time control are proposed. The Bangkok Transit System (BTS)Sky train Green Line in Bangkok, Thailand, is used for testing and analysing the proposed strategy. The paper is organized into six sections, and Sect. 2 gives basics of electric train simulation, covering train movement and performance, and DC power flow. The strategy for regenerative braking energy management with OBESS and problem formulation for optimal energy saving are described in Sects. 3 and 4, respectively. Section 5 presents simulation results and discussion. Finally, the conclusion is presented in Sect. 6.

\section{Simulation as a potential tool}

Electrified railway system is a complex system. Electrical characteristics, such as train vehicle performances and operation modes, as well as railway track characteristics, such as curve and gradient profiles, are considered. The single-train simulation (STS) consists of the train movement and performance calculation and the power flow calculation are described as follows:

\subsection{Train movement and performance calculation}

The performance of an electrified railway is calculated in the STS based on the standard operating curve. The train movement calculations are implemented using Newton's laws of motion, taking into account train resistance, track curve, gradients, speed restriction and modes of operation [16]. The net force applied to accelerate the train is as given in Eq. (1) which relates to Eqs. (2) and (3):

$F=F_{\mathrm{T}}-R=M_{\mathrm{eff}} \alpha$,

$R=F_{\mathrm{r}}+F_{\mathrm{g}}+F_{\mathrm{c}}$,

$M_{\mathrm{eff}}=M_{\mathrm{t}}\left(1+\lambda_{\mathrm{w}}\right)+M_{\mathrm{l}}$,

where $F$ is the net force $(\mathrm{N}), M_{\text {eff }}$ is the effective mass $(\mathrm{kg})$, $\alpha$ is a train acceleration rate $\left(\mathrm{m} / \mathrm{s}^{2}\right), F_{\mathrm{T}}$ is the tractive effort of a train $(\mathrm{N}), R$ is the overall resistance force of a train $(\mathrm{N}), F_{\mathrm{r}}$ is the running resistance force $(\mathrm{N}), F_{\mathrm{g}}$ is the gradient resistance force of a train $(\mathrm{N}), F_{\mathrm{c}}$ is the curve resistance force of a train $(\mathrm{N}), M_{\mathrm{t}}$ is the tare mass $(\mathrm{kg}), \lambda_{\mathrm{w}}$ is the rotary allowance, and $M_{1}$ is the freight or passenger load $(\mathrm{kg})$. With a sufficient small step time update, the train performances are calculated according to the mode of train operations. During any journey between two adjacent service stations, the operating mode is simply determined by four consecutive modes with appropriated speed control strategy, e.g., hysteresis control, proportional control [17].

The running resistance force including aerodynamic and the rolling resistance force or the frictional force of a train are described by the Davis equation in Eq. (4):

$F_{\mathrm{r}}=A+B v+C v^{2}$,

where $v$ is a train speed $(\mathrm{km} / \mathrm{h})$ and the coefficients $A(\mathrm{kN})$, $B(\mathrm{kNh} / \mathrm{km})$ and $C\left(\mathrm{kNh}^{2} / \mathrm{km}^{2}\right)$ are constants called Davis coefficients [18].

A train is modelled as homogeneous strips with equal weights. This gives a more realistic and accurate model for simulation. Gradient resistance force of a train covering a route section which may not have the same slope is given by Eqs. (5) and (6):

$F_{\mathrm{g}}=\mathrm{g} m_{1} n_{1}+\mathrm{g} m_{2} n_{2}+\ldots+\mathrm{g} m_{\mathrm{k}} n_{\mathrm{k}}$,

$m_{\mathrm{k}}=M_{\mathrm{eff}}\left(L_{\mathrm{k}} / L_{\mathrm{t}}\right)$,

where $\mathrm{g}$ is the gravitational constant $\left(9.81 \mathrm{~m} / \mathrm{s}^{2}\right), m_{\mathrm{k}}$ is the mass of the train covering a distance $S_{\mathrm{k}}$ which is determined by the number of different slopes throughout the length of the train, $n_{\mathrm{k}}$ is a slope of a distance (section) $S_{\mathrm{k}}$, $L_{\mathrm{k}}$ is the length of a train covering a distance $S_{k}$, and the sum of $L_{1}$ to $L_{\mathrm{k}}$ is equal to $L_{\mathrm{t}}$ and $L_{\mathrm{t}}$ is the length of a train.

Curve resistance force accounts for energy dissipation at the wheel-rail interface due to sliding, creep and friction. The force is inversely proportional to the radius of the 


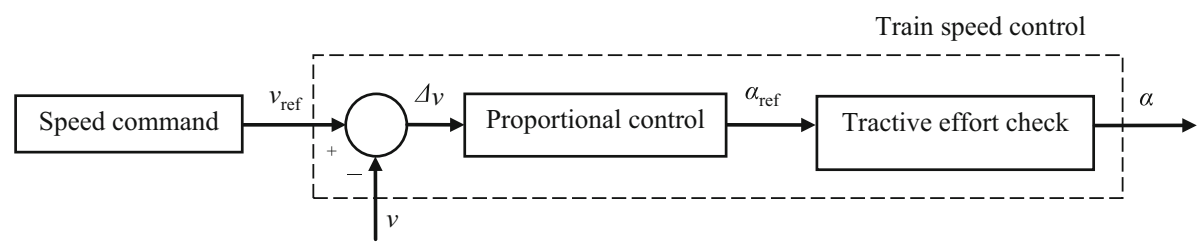

Fig. 1 Proportional control method for train speed control

curved track. The empirical formula of the curve resistance force is the Roeckl's formula in Eq. (7) [19]:

$F_{\mathrm{c}}=\left\{\begin{array}{l}\frac{6.3}{r(s)-55} M_{\mathrm{eff}} ; \text { for } r(s) \geq 300 \mathrm{~m} \\ \frac{4.91}{r(s)-30} M_{\mathrm{eff}} ; \text { for } r(s)<300 \mathrm{~m},\end{array}\right.$

where $r(s)$ is the curve radius.

Train speed is controlled by proportional control that calculates acceleration rate from speed mismatch between the actual feedback and the desired speed as presented in Fig. 1. The speed control command is used to determine train operation mode. In this paper, there are three operating modes in train speed control: (1) running mode, (2) braking mode and (3) station stop mode. The provided tractive effort depends on the applied speed control strategy.

Power consumed by a train $\left(P_{\mathrm{tr}}\right)$ is a summation of tractive power $\left(P_{\mathrm{ta}}\right)$, ESS power $\left(P_{\mathrm{ESS}}\right)$ and an auxiliary power $\left(P_{\text {aux }}\right)$ as given in (8) [20]:

$P_{\mathrm{tr}}=P_{\mathrm{ta}}+P_{\mathrm{ESS}}+P_{\mathrm{aux}}$,

$P_{\mathrm{ta}}=\left\{\begin{array}{l}\frac{F_{\mathrm{T}}}{\eta} \times v \text { if } F_{\mathrm{T}} \geq 0, \\ \eta F_{\mathrm{T}} \times v \text { if } F_{\mathrm{T}}<0,\end{array}\right.$

$P_{\mathrm{ESS}}=\left\{\begin{array}{l}P_{\text {charge }} \text { if with the ESS and charging mode, } \\ -P_{\mathrm{dis}} \text { if with the ESS and discharging mode, } \\ 0 \text { if without the ESS, }\end{array}\right.$

where $\eta$ denotes the efficiency of mechanical output power conversion at the wheels to the electrical input power, $P_{\text {charge }}$ and $P_{\text {dis }}$ are the charge and discharge power of the OBESS, respectively.

\subsection{DC traction power supply}

In this paper, a computer-based simulation for a train movement integrated with power supply interface is carried out. The DC power network solver needs the locations and the consumed power output data of the traction substation (TSS). Locations data are applied to calculate a system conductance matrix at each calculation step. The power consumption of a train is used to determine the entire power demands of the DC power supply network, which is defined as load bus in the power network calculation. Generally, a solution of the circuit analysis is obtained by loop equations or nodal equations. With the network of the DC-electrified railway system, the nodal equations are systematic and easily solved by a computer program [21].

Assuming a simplified Norton equivalent circuit of the DC traction power network as shown in Fig. 2, where $d$ is the position of a train, $L_{\mathrm{tss}}$ is the distance between two substations, $I_{\mathrm{TSS}}$ and $I_{\mathrm{s}}$ are substation current and substation short-circuit current, respectively, $I_{\text {tr }}$ is a train current, $R_{\mathrm{S}}$ is a substation short-circuit resistance, $R_{\text {cond }}$ and $R_{\text {rail }}$ are the conductor rail and the running rail resistances, respectively. $R_{\mathrm{SE}}$ and $G_{\mathrm{RE}}$ are the traction substation ground resistance and the rail-to-earth conductance, respectively. A train model is presented by a controlled current model, $I_{\text {tr }}=P_{\text {tr }} / V_{\text {tr }}$. In this paper, the current injection method (CIM) [1] has been applied in the power flow calculation. The updated parameters are obtained by setting up the nodal equations as in Eq. (11). The conductance matrix $\boldsymbol{G}$ in each step of a train travelling is updated by considering the positions of a train and the power consumption is possibly changed according to the train operation modes. An iteration is stopped when the error of the pre-stepped voltage vector at the current iteration is less than the criteria value.

$\boldsymbol{I}_{6 \times 1}=\boldsymbol{G}_{6 \times 6} \boldsymbol{V}_{6 \times 1}$,

where $\boldsymbol{I}=\left[\begin{array}{llllll}\boldsymbol{I}_{\mathrm{TSS} 1} & -\boldsymbol{I}_{\mathrm{TSS} 1} & \boldsymbol{I}_{\mathrm{TSS} 2} & -\boldsymbol{I}_{\mathrm{TSS} 2} & -\boldsymbol{I}_{\mathrm{tr}} & \boldsymbol{I}_{\mathrm{tr}}\end{array}\right]^{\mathrm{T}}$.

\section{Strategy for regenerative braking energy management with OBESS}

\subsection{Regenerative braking energy management with the OBESS}

In the viewpoint of energy management in electrified railway operation, Energy Storage Devices (ESDs) are supposed to reduce train energy consumption by recuperating braking energy and supply it back to the train when needed [22]. When a train is braking, the traction motors can act like generators. As previously mentioned, regenerative braking system with OBESS is more efficient than 


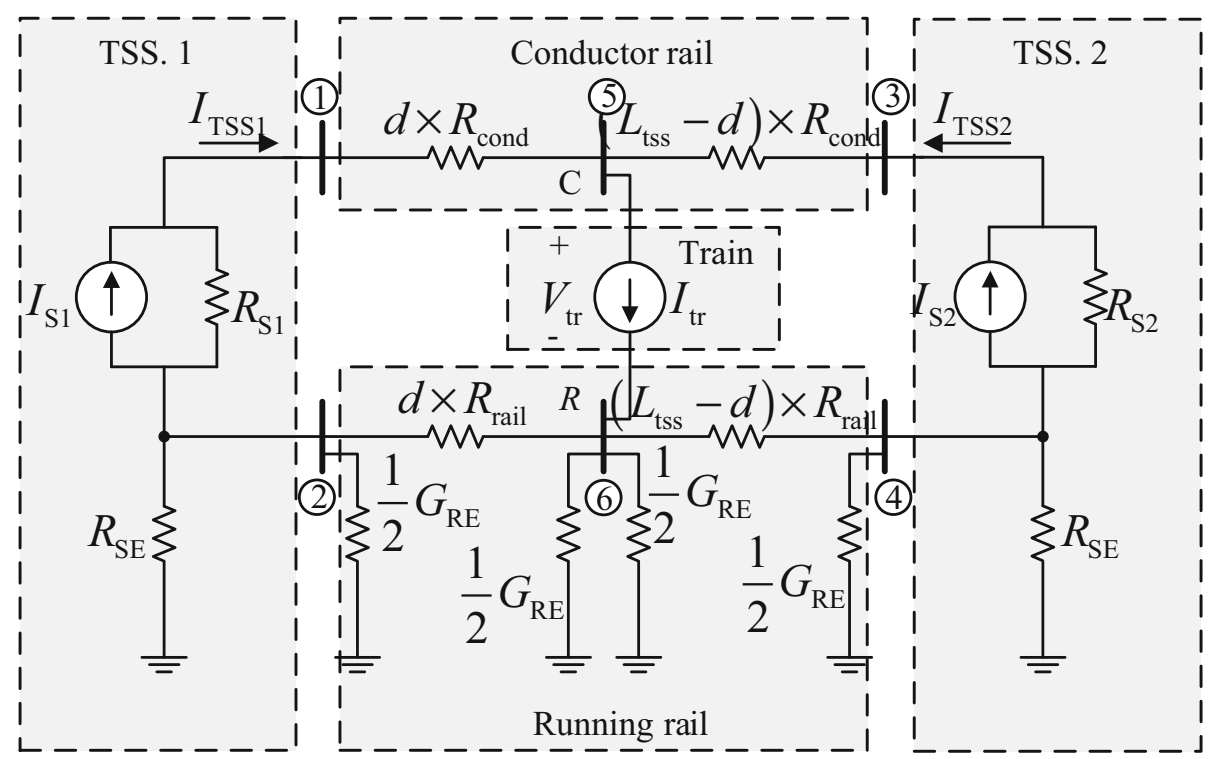

Fig. 2 Equivalent circuit representing the DC traction power supply

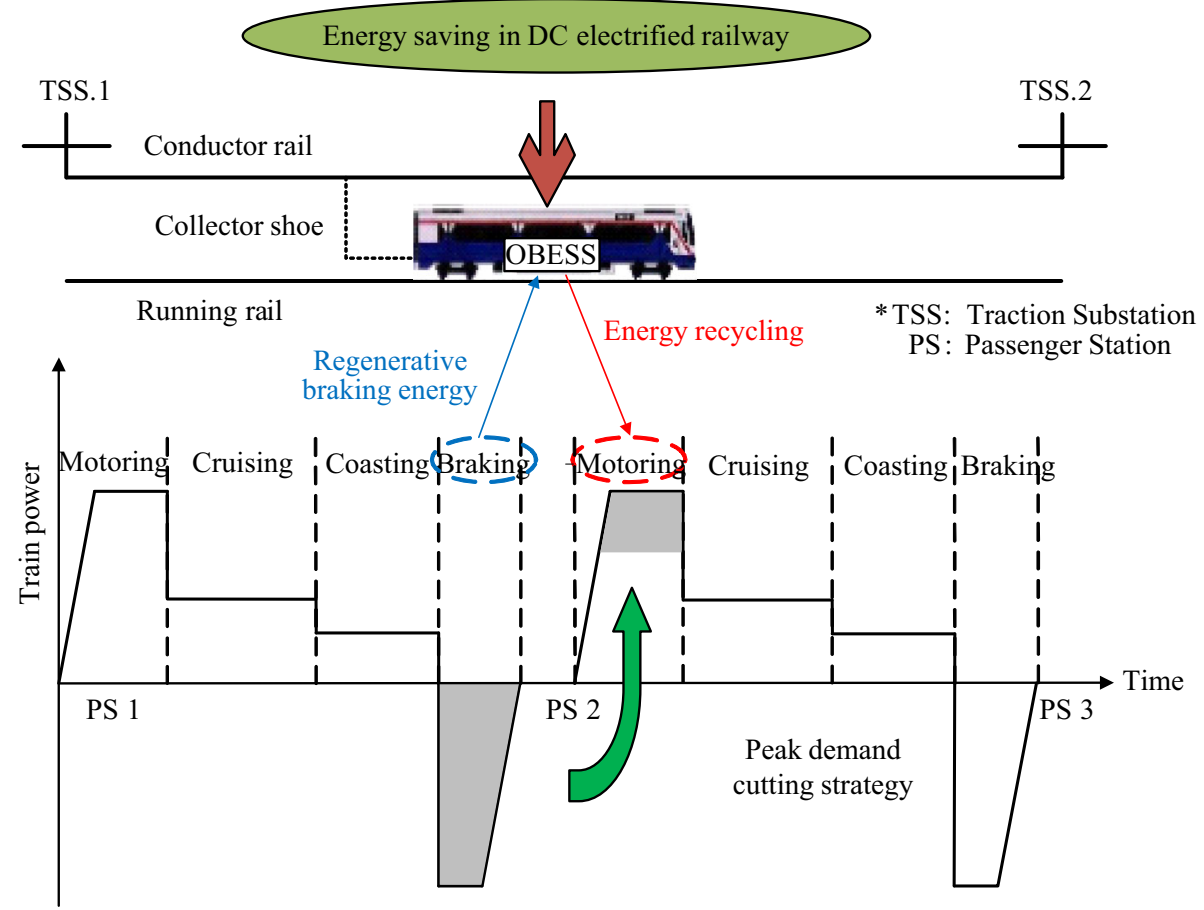

Fig. 3 Regenerative braking energy management with OBESS

the one with TESS due to absence of line losses. Currently, electrochemical double-layer capacitors (EDLCs) have shown great potential to be used as on-board energy storage devices (OBESD) [4]. The characteristics of EDLCs are fast charge and discharge capability, high power density, long life cycles and low internal resistance [23]. The main purpose of the OBESS in this paper is peak power compensation by recuperating and resupplying train braking energy as summarized in Fig. 3.

\subsection{Proposed peak cutting strategy}

Peak power reduction during train acceleration is achieved by controlling charge and discharge of the OBESS. Train power flows when braking and accelerating are shown in 


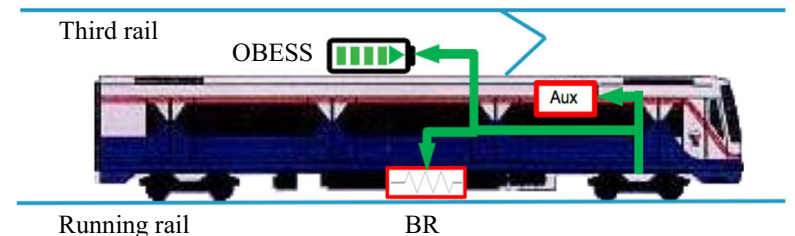

(a) During braking (charge)

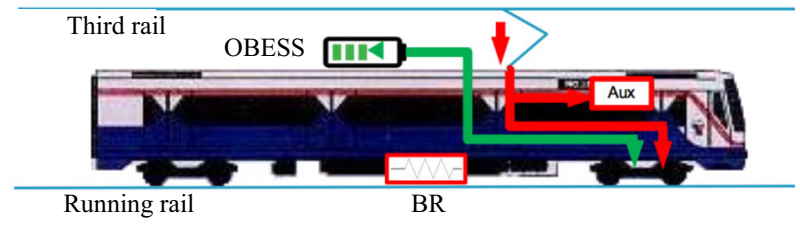

(b) During accelerating (discharge)

Fig. 4 Power flow in the train equipped with OBESS

Fig. 4. The MITRAC energy saver unit based on EDLC produced by Bombardier Company is chosen for the ESS in this paper because it has high energy density ( $\mathrm{Wh} / \mathrm{kg}$ ) per module compared to the products from other companies [24].

Charge and discharge of OBESD depend on train power demand and SOC of the OB ESD. When a train is braking the OBESD is recharged if it is not fully charged, otherwise the braking energy is dissipated in braking resistors. When a train is motoring, auxiliary systems draw power from the power supply via conducting (third) rail while the tractive is supplied from a DC substation and from OBESS if discharging criteria of the OBESS is reached. This means that the peak power of the power supply is compensated by the stored energy from the OBESD. The flowchart of the energy management model is shown in Fig. 5.

\subsection{Charging algorithm}

Charging algorithm starts by checking if a train is braking. Regenerative braking power $\left(P_{\text {reg }}\right)$ is then calculated by Eq. (12) through Eq. (14), where $\eta_{\text {charge }}, \eta_{\text {motor }}, \eta_{\text {gear }}, \eta_{\text {inv }}$, $\eta_{\mathrm{ESS}}, \eta_{\text {chopper }}$ and $\eta_{\mathrm{ELDC}}$ are charge, motor, gear, inverter, ESS, chopper and ELDC efficiencies, respectively. The braking energy that is stored in the OBESS ( $\left.E_{\mathrm{ESS}}\right)$ can be calculated by Eq. (15). It is important to note that the regenerative braking energy is not supplied back to a substation, when the OBESD is fully charged and there is no adjacent moving train, the regenerative energy is dissipated by the braking resistors. The flowchart of the charging algorithm is summarized in Fig. 6.

$P_{\text {reg }}=P_{\text {charge }}=F_{\mathrm{T}} \times v \times \eta_{\text {charge }}$,

$\eta_{\text {charge }}=\eta_{\text {motor }} \times \eta_{\text {gear }} \times \eta_{\text {inv }} \times \eta_{\text {ESS }}$,

$\eta_{\text {ESS }}=\eta_{\text {chopper }} \times \eta_{\text {EDLC }}$,

$E_{\mathrm{ESS}}(t+\Delta t)=E_{\mathrm{ESS}}(t)+P_{\mathrm{reg}} \Delta t$,

\subsection{The discharging algorithm}

Discharging algorithm starts by checking if a train is in acceleration mode. The tractive power during train motoring is supplied from a DC substation via conductor

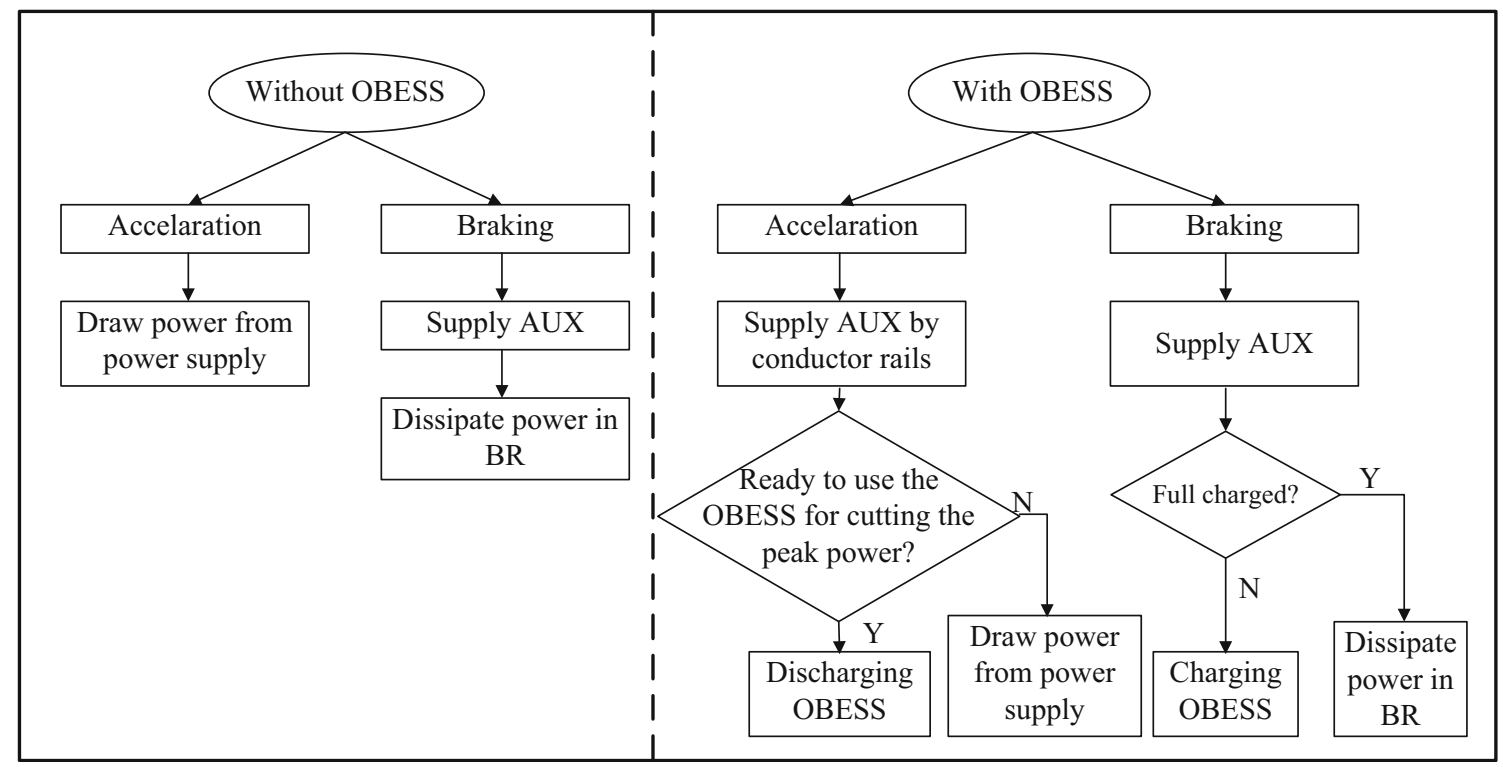

Fig. 5 Flowchart of the energy management model 


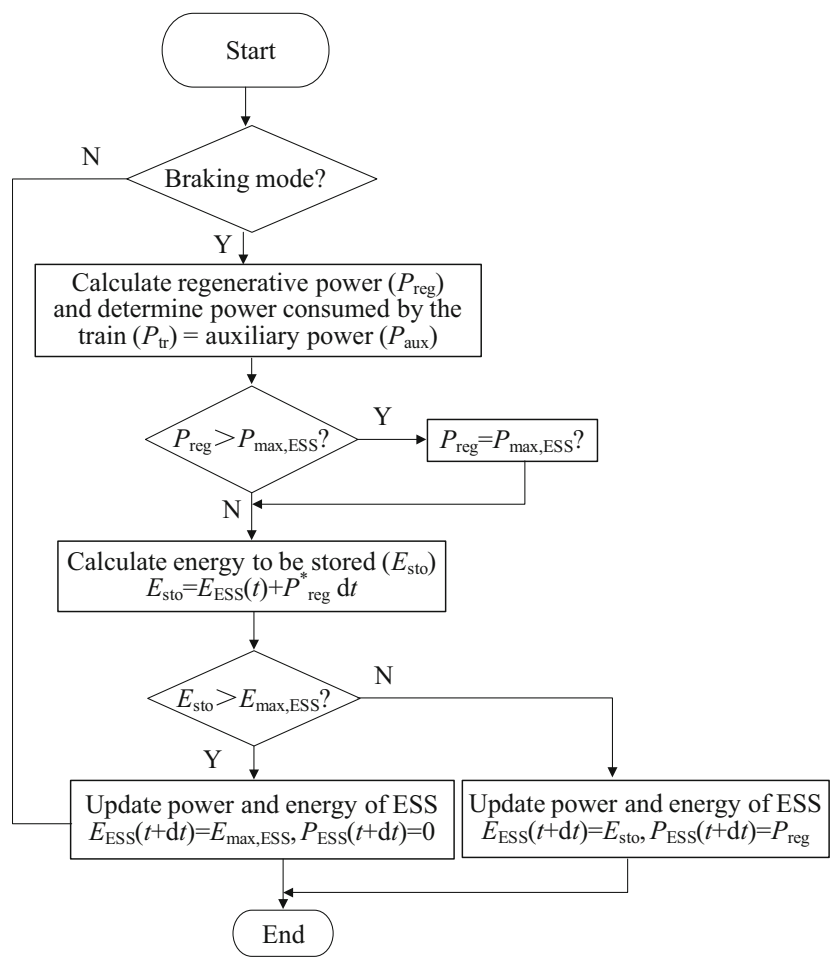

Fig. 6 Flowchart of the charge control for OBESS

rail and from OBESS if discharging criteria of the OBESS is reached. Power is drawn from the OBESS when its state of charge (SOC) is greater than the minimum limit and the required train power is more than the difference between the estimated peak power $\left(P_{\text {peak }}\right)$ and the maximum allowable discharging power from the OBESS $\left(P_{\mathrm{dis}, \max }\right)$, see Eq. (16). Flow chart of OBESS discharge control is shown in Fig. 7. The discharged power and energy of the OBESS $\left(E_{\mathrm{ESS}}\right)$ are calculated by Eqs. (17) and (18), respectively.

$P_{\mathrm{tr}} \geq P_{\text {peak }}-P_{\mathrm{dis}, \max }$,

$P_{\text {dis }}(t+\Delta t)=\left(P_{\mathrm{ta}}(t+\Delta t)+P_{\text {aux }}-P_{\text {start }}\right) / \eta_{\text {discharge }}$,

$E_{\mathrm{ESS}}(t+\Delta t)=E_{\mathrm{ESS}}(t)-\left(P_{\mathrm{dis}}(t+\Delta t) \times \Delta t\right)$.

\section{Problem formulations for optimal energy saving}

\subsection{Objective function}

The optimization objective of the paper is to maximize total saved energy at substations $(\phi)$, defined as in Eq. (19).

Maximize $\phi=1-\left(\sum_{i=1}^{N_{\text {TSS }}} E_{\text {sub }, i}^{\text {ess }} / \sum_{i=1}^{N_{\text {TSS }}} E_{\mathrm{sub}, i}^{\mathrm{noss}}\right)$, where $E_{\mathrm{sub}, i}^{\mathrm{ess}}$ and $E_{\mathrm{sub}, i}^{\mathrm{noess}}$ are the energy consumption at substation $i$ with and without OBESS, respectively, and $N_{\text {TSS }}$ is the number of traction substations.

\subsection{Control parameters}

The following control parameters are used to maximize the objective function: number of the OBESS modules $\left(N_{\mathrm{ESS}}\right)$, initial SOC of the OBESS ( $\left(\mathrm{SOC}_{\text {start }}\right)$, a gain of deceleration control $\left(k_{\mathrm{dec}}\right)$ and coasting point $\left(L_{\mathrm{cosst}}\right)$. Trip time is controlled by $k_{\text {dec }}$ and $L_{\text {coast }}$ as presented in Fig. 8 .

\subsection{Constraints}

The constraints of the optimization are given as follows: Inequality constraints:

$\mathrm{SOC}_{\text {limit }}^{\text {lower }} \leq \mathrm{SOC} \leq \mathrm{SOC}_{\text {limit }}^{\text {upper }}$,

$N_{\mathrm{ESS}}^{\min } \leq N_{\mathrm{ESS}} \leq N_{\mathrm{ESS}}^{\max }$,

$P_{\mathrm{ESS}}^{\min } \leq P_{\mathrm{ESS}} \leq P_{\mathrm{ESS}}^{\max }$,

$k_{\mathrm{dec}}^{\min } \leq k_{\mathrm{dec}} \leq k_{\mathrm{dec}}^{\max }$,

$L_{\text {coast }}^{\min } \leq L_{\text {coast }} \leq L_{\text {coast }}^{\max }$,

where $\mathrm{SOC}_{\text {limit }}^{\text {lower }}$ and $\mathrm{SOC}_{\text {limit }}^{\text {upper }}$ are lower and upper limit of the SOC, $N_{\mathrm{ESS}}^{\min }$ and $N_{\mathrm{ESS}}^{\max }$ are minimum and maximum number of the OBESS modules, $P_{\mathrm{ESS}}^{\min }$ and $P_{\mathrm{ESS}}^{\max }$ are minimum and maximum power of the OBESS, $k_{\mathrm{dec}}^{\min }$ and $k_{\mathrm{dec}}^{\max }$ are minimum and maximum gain of the deceleration control, and $L_{\text {coast }}^{\min }$ and $L_{\text {coast }}^{\max }$ are minimum and maximum coasting point.

Equality constraint:

$T_{\text {trip }}=T_{\text {trip }}^{\text {nominal }}$,

$\mathrm{SOC}_{\text {max }}=\mathrm{SOC}_{\text {limit }}^{\text {upper }}$,

$\mathrm{SOC}_{\mathrm{end}}=\mathrm{SOC}_{\text {start }}$,

where $T_{\text {trip }}$ is the trip time, $\mathrm{SOC}_{\max }$ and $\mathrm{SOC}_{\text {end }}$ are the maximum and final SOC of the OBESS, respectively.

In this paper, the genetic algorithm (GA) [25] has been implemented to find the optimal control parameters for maximizing the total energy saving of substations during the proposed journey. The flowchart of the simulator is summarized in Fig. 9.

\section{Simulation results and discussion}

\subsection{Test system}

The Silom Line of BTS Sky train used in this paper was the first mass transit line to commence service in Bangkok, 
Finding a condition to start the OBESS function

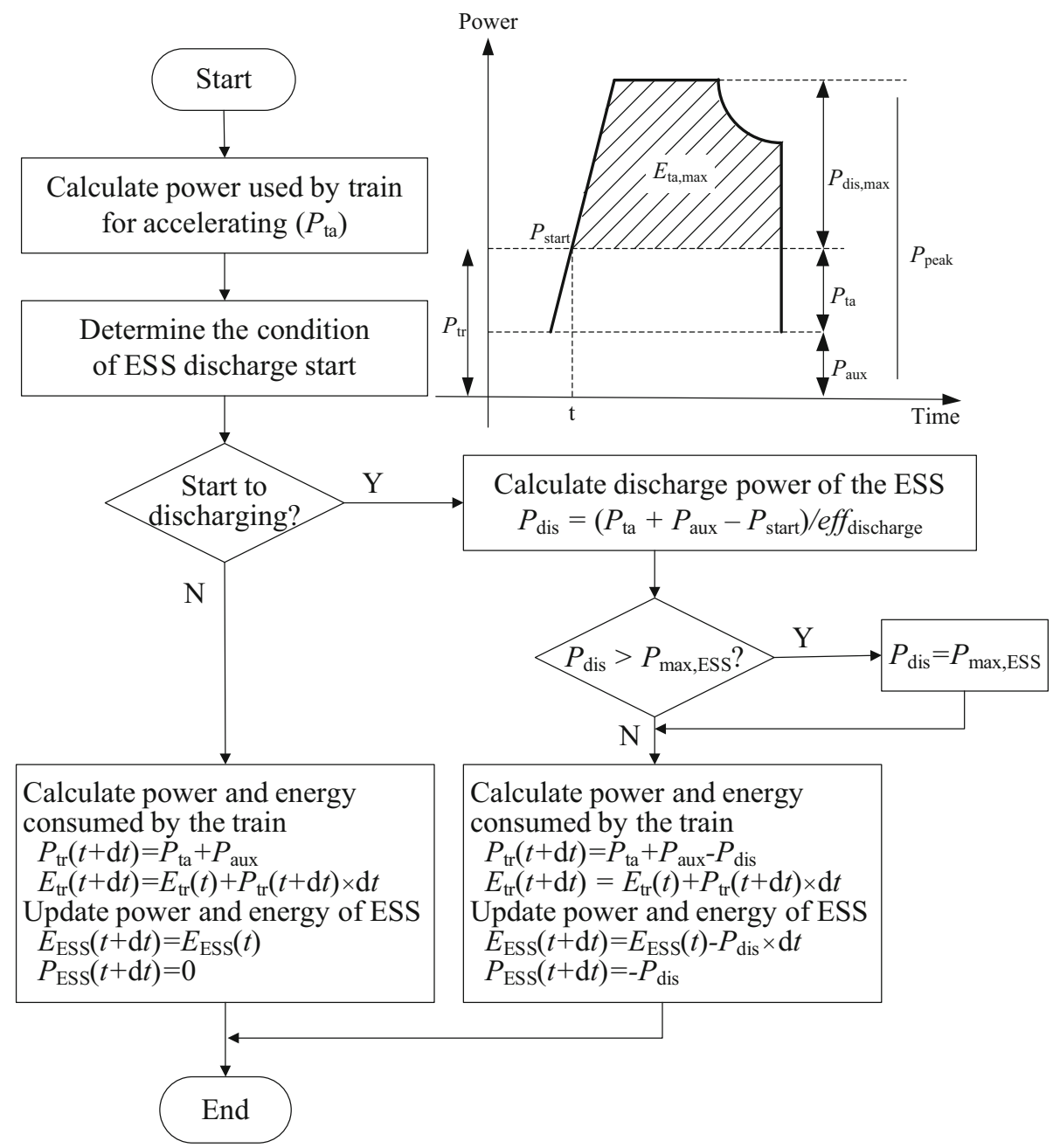

Fig. 7 Flowchart of the discharge control for OBESS

Thailand. The line has a service distance of $13.65 \mathrm{~km}, 13$ service stations (W1-S12) and 7 DC traction substations as shown in Fig. 10 [16]. A train service starts from station $\mathrm{W} 1$ and terminates at station S12. The system parameters for simulation are listed in Table 1, and the simulation is done by MATLAB program on an Intel Core i5 $2.53 \mathrm{GHz}$, 4.0 GB RAM computer. A train speed profile with the speed limit of the southbound train (Based case) is shown in Fig. 11. Three cases are considered in the simulation and compared to the base case (without OBESS) as shown in Table 2 , and $k_{\text {dec }}$ and $L_{\text {coast }}$ are only considered when train speed is equal or greater than $60 \mathrm{~km} / \mathrm{h}$ (from S6 to S12). The GA parameters used in the simulation are presented in Table 3. The SOC of the OBESS is maintained between $20 \%$ and $95 \%$ to maintain the life cycle of the OBESS.

From the simulation, optimal parameters are given in Table 4. It can be seen that the total number of modules and the initial SOC of the OBESS for both Case 1 and Case

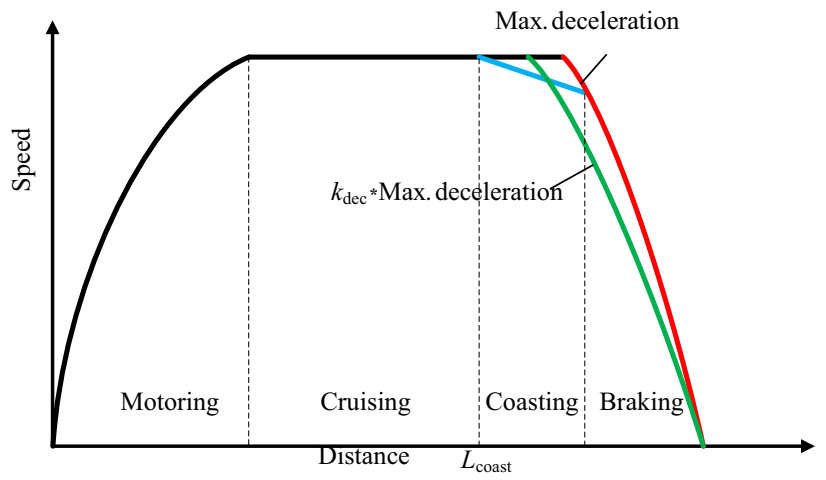

Fig. 8 Operating modes for the train

2 are 11 modules and $44.8 \%$, respectively, whereas 10 modules and $40.9 \%$ of the initial SOC of the OBESS for Case 3 obtains the best fitness function. Maximum SOC of 
Table 1 The system conditions for simulation

\begin{tabular}{|c|c|c|}
\hline Specific data & & Information \\
\hline \multicolumn{3}{|l|}{ Train parameters } \\
\hline Voltage & Nominal voltage & $750 \mathrm{~V}$ \\
\hline \multirow[t]{2}{*}{ Weight } & Tare weight & 153 ton \\
\hline & Payload AW3 & 75 ton \\
\hline \multirow[t]{3}{*}{ Movement feature } & Max. speed & $80 \mathrm{~km} / \mathrm{h}$ \\
\hline & Max. acceleration & $0.87 \mathrm{~m} / \mathrm{s}^{2}$ \\
\hline & Max. deceleration & $1.00 \mathrm{~m} / \mathrm{s}^{2}$ \\
\hline \multirow[t]{2}{*}{ Efficiency } & Gear, motor, inverter & $98 \%, 88 \%, 98 \%$ \\
\hline & EDLC, chopper & $86 \%, 95 \%$ \\
\hline Auxiliary power & Constant load & $270 \mathrm{~kW}$ \\
\hline Train resistance & $A=4025, B=118.67, C=0.871$ & \\
\hline \multicolumn{3}{|l|}{ Power system parameters } \\
\hline Traction substation & No-load voltage rated power & $\begin{array}{l}790 \mathrm{~V} \\
2550 \mathrm{kVA}(\mathrm{CEN}, \mathrm{S} 02, \mathrm{~S} 05, \mathrm{~S} 07) \\
3300 \mathrm{kVA}(\mathrm{S} 09, \mathrm{~S} 11, \mathrm{~S} 12)\end{array}$ \\
\hline \multirow[t]{3}{*}{ Third rail and running rail } & Third rail resistance & $8.23 \mathrm{~m} \Omega / \mathrm{km}$ \\
\hline & Running rail resistance & $40.46 \mathrm{~m} \Omega / \mathrm{km}$ \\
\hline & Conductivity to earth & $0.1 \mathrm{~S} / \mathrm{km}$ \\
\hline \multicolumn{3}{|l|}{ OBESS parameters } \\
\hline \multirow[t]{3}{*}{ MITRAC energy saver [26] } & Installed energy & $1 \mathrm{kWh} /$ module \\
\hline & Max output power & $300 \mathrm{~kW} /$ module \\
\hline & Weight & $428 \mathrm{~kg} /$ module \\
\hline
\end{tabular}

Table 2 Conditions of simulation in each case

\begin{tabular}{lll}
\hline Case & OBESS & Trip time control \\
\hline Based & Without & Max. deceleration \\
1 & With & $k_{\text {dec }} *$ Max. deceleration \\
2 & With & $L_{\text {coast }}+$ Max. deceleration \\
3 & With & $L_{\text {coast }}+k_{\text {dec }} *$ Max. deceleration \\
\hline
\end{tabular}

the OBESS and trip time for all cases are $95 \%$ and 1649 s, respectively.

Train speed profiles from station S6 to station S12 are shown in Fig. 12. Speed profiles for different cases are different according to the trip time control of each case. Figure 13 presents the OBESS operation, the state of charge is kept between $20 \%$ and $95 \%$. The OBESS is recharged during train braking and discharged during train motoring. The discharge controls of the OBESS in all cases depend on train power demand and SOC of the OBESS. In the base case, train voltage drops rapidly from 790 to $620 \mathrm{~V}$ after leaving the first station whereas in other cases with OBESS voltage regulation is improved as shown in Fig. 14. Figure 15 presents train power profile for southbound train direction, and the traction power of substations decreases as shown in Fig. 16 because the OBESS cuts peak power.
Table 3 GA parameters

\begin{tabular}{ll}
\hline Parameters & Values \\
\hline Control variables & \\
Number of the OBESS modules $\left(N_{\mathrm{ESS}}\right)$ & {$[8,14]$} \\
Initial SOC of the OBESS $\left(\mathrm{SOC}_{\mathrm{star}}\right)$ & {$[20,95]$} \\
Gain of deceleration control $\left(k_{\mathrm{dec}}\right)$ & {$[0.8,1]$} \\
Coasting point $\left(L_{\text {coast }}\right)$ & {$[200,2000]$} \\
Generation & $\mathrm{Nvar} \times 20$ \\
Population & $\mathrm{Nvar} \times 10$ \\
Crossover probability & 0.9 \\
Mutation probability & 0.1 \\
Function tolerance & $1 \times 10^{-6}$
\end{tabular}

* Nvar is the number of control variables

Considering the peak power cutting at the first traction substation (TSS1), the OBESS is unavailable because its SOC is lower than the appropriate level to start discharging. From the second substation (TSS2) and onwards, the OBESS is capable of supporting train acceleration power. In Table 5, the percentage of peak power reduction at TSS1 for Case 3 is less than other cases since the number of OBESS module and the initial SOC from GA optimization for Case 3 are different from Case 1 and Case 2, see Table 4. The trip time control only 
Table 4 Optimal parameters

\begin{tabular}{|c|c|c|c|}
\hline Parameters & Case 1 & Case 2 & Case 3 \\
\hline$N_{\text {ESS }}$ & 11 & 11 & 10 \\
\hline SOC $_{\text {start }}$ & $44.8 \%$ & $44.8 \%$ & $40.9 \%$ \\
\hline \multirow[t]{6}{*}{$k_{\mathrm{dec}}$} & $k_{\mathrm{dec}, 7}=0.80452$ & - & $k_{\mathrm{dec}, 7}=0.95216$ \\
\hline & $k_{\mathrm{dec}, 8}=0.84933$ & & $k_{\mathrm{dec}, 8}=0.94633$ \\
\hline & $k_{\mathrm{dec}, 9}=0.85840$ & & $k_{\mathrm{dec}, 9}=0.99529$ \\
\hline & $k_{\mathrm{dec}, 10}=0.92247$ & & $k_{\mathrm{dec}, 10}=0.97604$ \\
\hline & $k_{\mathrm{dec}, 11}=0.83889$ & & $k_{\mathrm{dec}, 11}=0.98407$ \\
\hline & $k_{\mathrm{dec}, 12}=0.86245$ & & $k_{\mathrm{dec}, 12}=0.97851$ \\
\hline \multirow[t]{6}{*}{$L_{\text {coast }}$} & - & $L_{\text {coast }, 7}=200.00$ & $L_{\text {coast }, 7}=304.72$ \\
\hline & & $L_{\text {coast }, 8}=202.89$ & $L_{\text {coast }, 8}=218.39$ \\
\hline & & $L_{\text {coast }, 9}=269.95$ & $L_{\text {coast }, 9}=280.00$ \\
\hline & & $L_{\text {coast } 10}=200.68$ & $L_{\text {coast }, 10}=209.32$ \\
\hline & & $L_{\text {coast }, 11}=200.00$ & $L_{\text {coast }, 11}=\mathrm{N} / \mathrm{A}$ \\
\hline & & $L_{\text {coast }, 12}=\mathrm{N} / \mathrm{A}$ & $L_{\text {coast }, 12}=200.00$ \\
\hline Fitness function $(\phi)$ & 0.13715 & 0.15248 & 0.15564 \\
\hline
\end{tabular}

N/A is no coasting

Table 5 The maximum peak power at TSS of each case

\begin{tabular}{|c|c|c|c|c|c|c|c|}
\hline Case & $P_{\mathrm{TSS} 1}(\mathrm{MW})$ & $P_{\mathrm{TSS} 2}(\mathrm{MW})$ & $P_{\mathrm{TSS} 3}(\mathrm{MW})$ & $P_{\mathrm{TSS} 4}(\mathrm{MW})$ & $P_{\mathrm{TSS} 5}(\mathrm{MW})$ & $P_{\mathrm{TSS} 6}(\mathrm{MW})$ & $P_{\mathrm{TSS} 7}(\mathrm{MW})$ \\
\hline Based & 3.04 & 2.00 & 2.23 & 2.19 & 2.18 & 2.16 & 2.48 \\
\hline \multirow[t]{2}{*}{1} & 1.74 & 0.73 & 1.75 & 1.31 & 1.45 & 1.56 & 1.22 \\
\hline & [42.68] & [63.49] & [21.39] & [40.05] & {$[33.62]$} & [27.74] & [50.89] \\
\hline \multirow[t]{2}{*}{2} & 1.74 & 0.73 & 1.75 & 1.31 & 1.47 & 1.59 & 1.22 \\
\hline & [42.68] & [63.49] & [21.39] & [40.05] & [32.81] & [26.12] & [50.89] \\
\hline \multirow[t]{2}{*}{3} & 1.95 & 0.73 & 1.75 & 1.31 & 1.48 & 1.56 & 1.22 \\
\hline & {$[35.85]$} & [63.49] & [21.38] & [40.06] & [31.99] & [27.74] & [50.95] \\
\hline
\end{tabular}

[*] is the percentage deviation compared with the case that has no OBESS

Table 6 Performance index of the power supply network

\begin{tabular}{|c|c|c|c|c|}
\hline Item (unit) & Based case & Case 1 & Case 2 & Case 3 \\
\hline \multirow[t]{2}{*}{ Energy consumed by train (kWh) } & \multirow[t]{2}{*}{298.95} & 260.90 & 256.08 & 255.13 \\
\hline & & [12.73] & [14.34] & [14.66] \\
\hline \multirow[t]{2}{*}{ Energy consumption at substation (kWh) } & \multirow[t]{2}{*}{314.20} & 271.11 & 266.29 & 265.30 \\
\hline & & [13.71] & {$[15.25]$} & [15.56] \\
\hline \multirow[t]{2}{*}{ Energy losses (kWh) } & \multirow[t]{2}{*}{15.25} & 10.20 & 10.21 & 10.16 \\
\hline & & {$[33.07]$} & {$[33.03]$} & [33.34] \\
\hline \multirow[t]{2}{*}{ Regenerated energy available (kWh) } & \multirow[t]{2}{*}{87.55} & 72.15 & 66.94 & 66.29 \\
\hline & & {$[17.58]$} & [23.54] & [24.28] \\
\hline \multirow[t]{2}{*}{ Energy wasted in brake resistor (kWh) } & \multirow[t]{2}{*}{71.13} & 0.33 & 0.63 & 0.12 \\
\hline & & [99.54] & [99.12] & [99.83] \\
\hline Recovery coefficient (\%) & - & 59.72 & 71.58 & 73.76 \\
\hline
\end{tabular}

[*] is the percentage deviation compared with the case that has no OBESS 


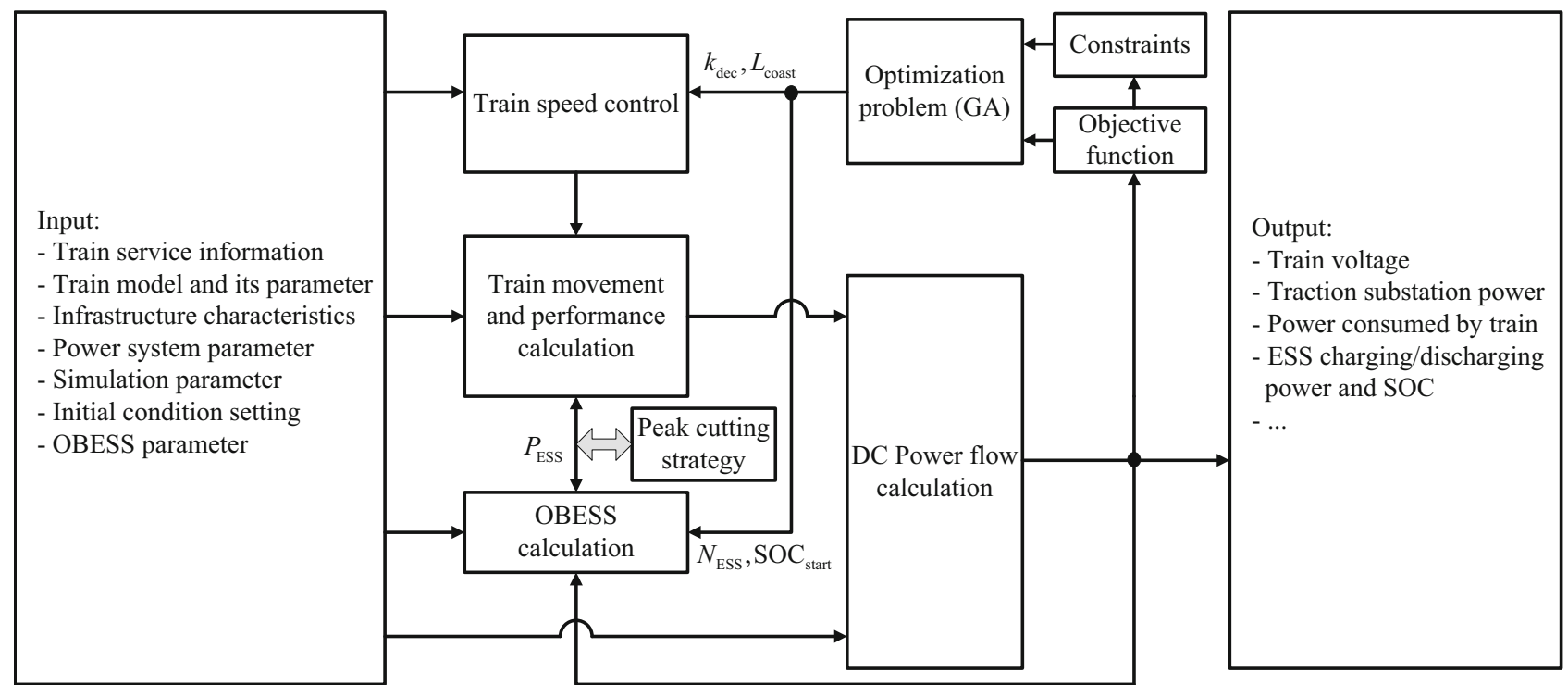

Fig. 9 Optimization of the OBESS operation and speed profile to maximize total saved energy at substations

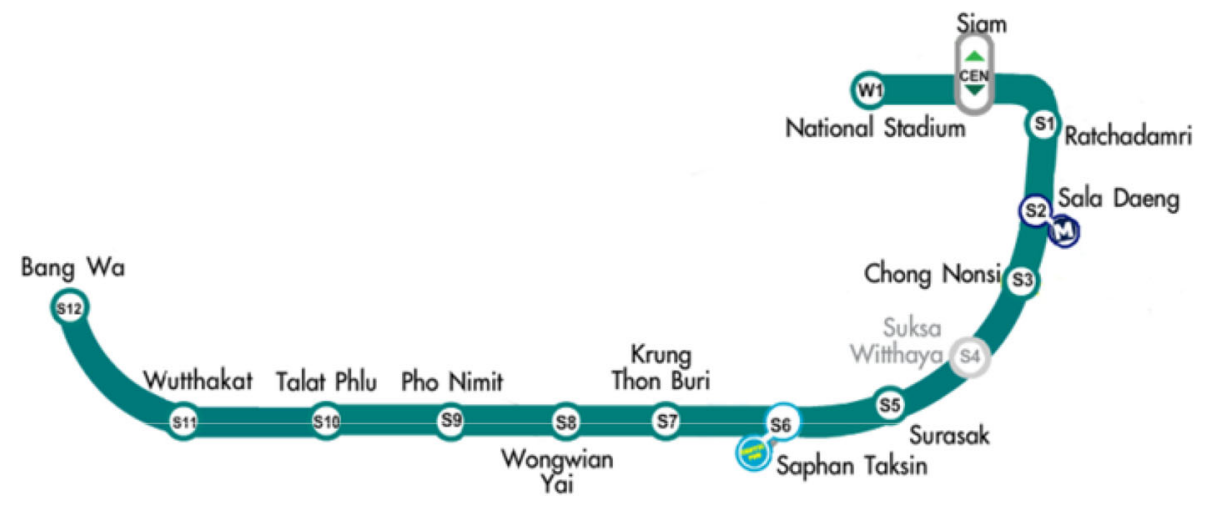

Fig. 10 BTS Sky train Silom Line, Bangkok, Thailand

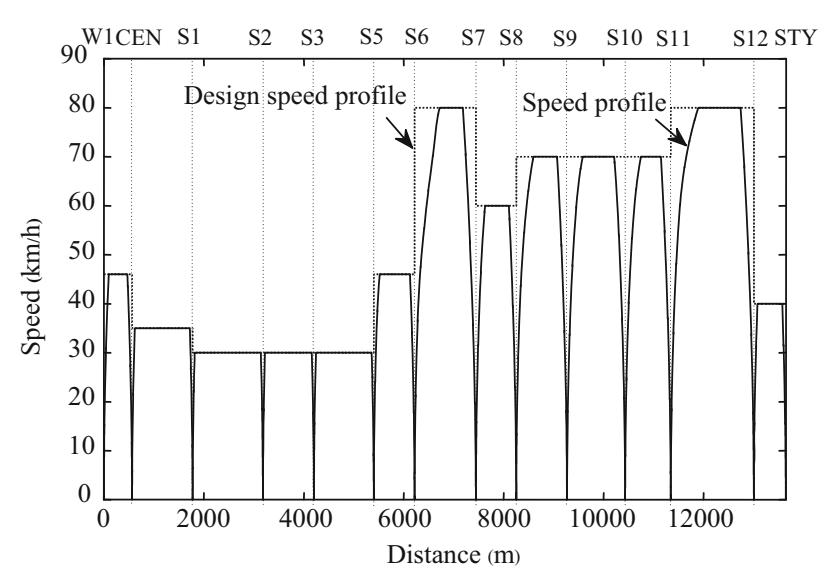

Fig. 11 Train speed profile of southbound direction (base case)

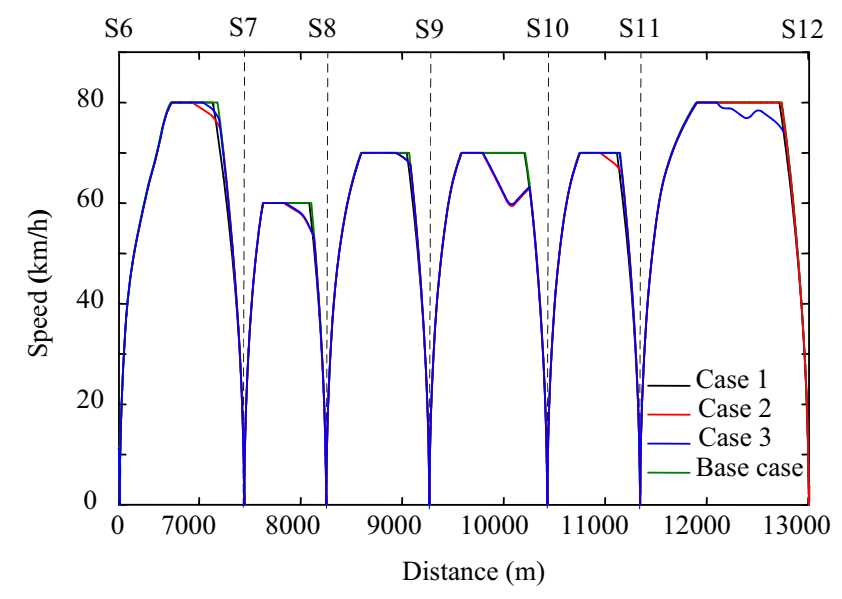

Fig. 12 Optimal train speed profile (S6-S12) of each case 


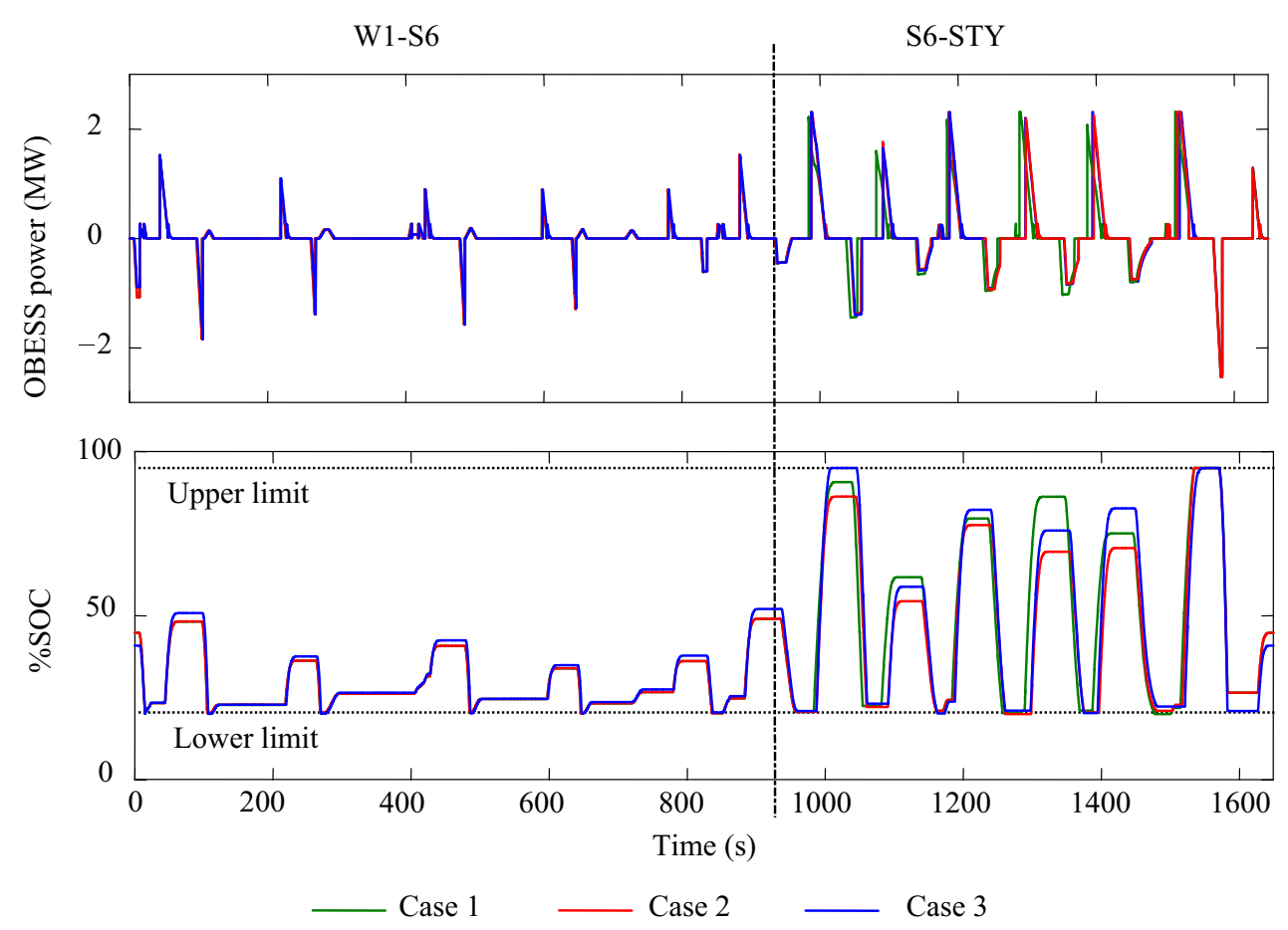

Fig. 13 ESS power and \%SOC

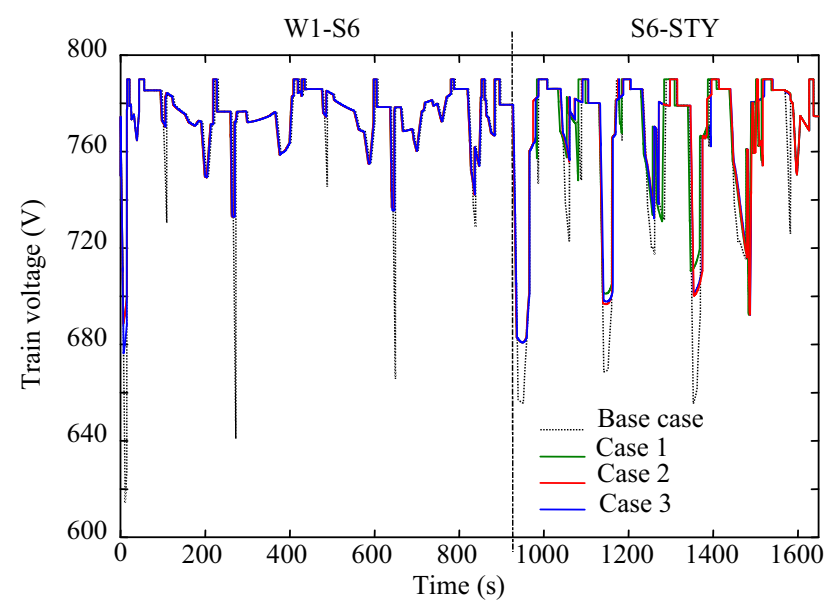

Fig. 14 Train voltage profile

affects the peak power at TSS5, TSS6 and TSS7 accordingly, and the peak powers of all cases are very close to one another. With the proposed peak cutting algorithm, a $63.49 \%$ maximum peak power reduction is achieved at TSS2 (from 2 to $0.73 \mathrm{MW}$ ).

The simulation is based on a single train travelling a single journey in the southbound direction of each case compared with the base case (with no OBESS) as shown in Table 6. Regarding the energy saving, the total energy drawn by a train is saved by $12.73 \%, 14.34 \%$ and $14.66 \%$ in Case 1, Case 2 and Case 3, respectively. This reveals

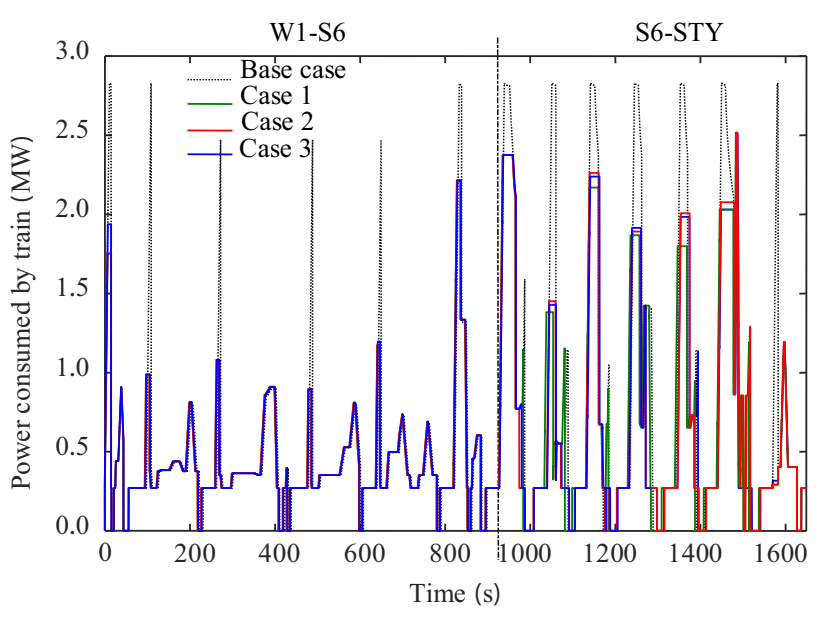

Fig. 15 Power consumed by train

that the motive energy saving is affected by the initial SOC of the OBESS. The total energy consumed by the traction substation is saved by $13.71 \%, 15.25 \%$ and $15.56 \%$ in Case 1, Case 2 and Case 3, respectively. The net energy losses for each case are the same, which is $10 \mathrm{kWh}$, that is $33 \%$ reduction from the base case. Available regenerative braking energy is the energy generated from the train braking (not energy supplied to the auxiliary systems or the OBESS), it can be seen that Case 3 has the highest available regenerative braking energy. The dissipated energy by the electric braking resistor is saved by $99.54 \%, 99.12 \%$ 

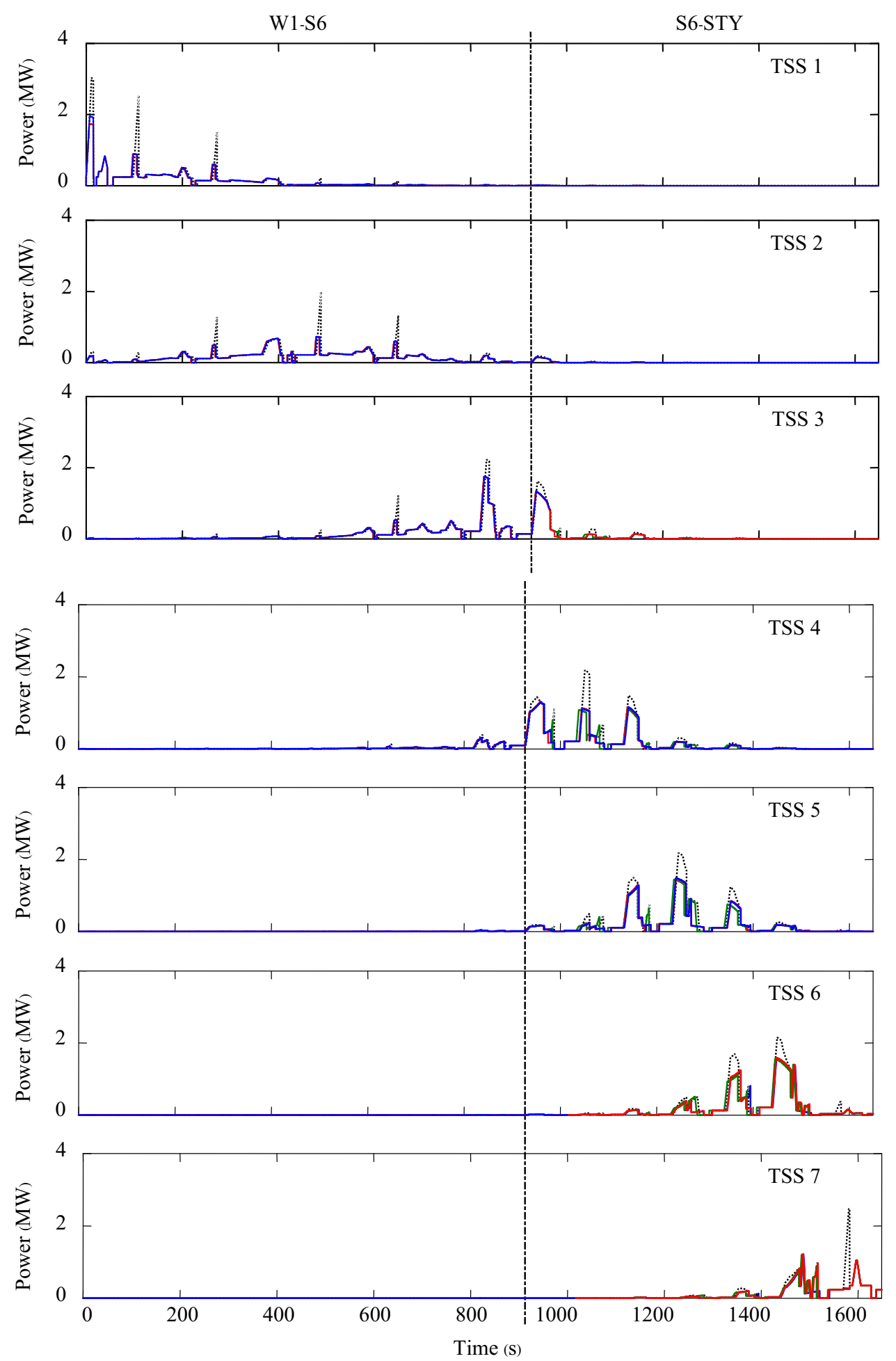

Base case

Case 1

Case 2

Case 3

Fig. 16 Traction substation power at TSS

and $99.83 \%$ in Case 1, Case 2 and Case 3, respectively. The recovery coefficient proposed in this paper is the proportion between the total energy savings measured at substations and the regenerated braking energy produced by a train; Case 3 achieves recovery coefficient of $73.76 \%$ which is the highest. 


\section{Conclusion}

This paper presents a study on optimal energy saving in DCelectrified railway system by using OBESS. Substation peak power reduction and evaluating power supply network performance achieved by using peak demand cutting strategy are the objectives of the study. Criteria for OBESS design, regenerative braking energy management strategy and trip time control are proposed. Track model used in the simulation is based on data from Bangkok Transit System (BTS)-Sky train Silom Line in Thailand. The proposed system is thus effectively compared with the present system (base case) that uses no OBESS. A $15.56 \%$ of the energy saving at the traction substation is achieved by the proposed strategy, peak power is reduced by $63.49 \%$ at TSS2, and the number of OBESS modules can also be reduced by controlling the trip time of the coasting motion together with the deceleration control (Case 3). The initial SOC of the OBESS has a huge effect on peak power cutting only at the first traction substation.

Open Access This article is distributed under the terms of the Creative Commons Attribution 4.0 International License (http:// creativecommons.org/licenses/by/4.0/), which permits unrestricted use, distribution, and reproduction in any medium, provided you give appropriate credit to the original author(s) and the source, provide a link to the Creative Commons license, and indicate if changes were made.

\section{References}

1. Kulworawanichpong T (2015) Multi-train modeling and simulation integrated with traction power supply solver using simplified Newton-Raphson method. J Mod Transp 23(4):241-251. doi:10. 1007/s40534-015-0086-y

2. Khayyam S, Lakhdar H, Ponci F, Monti A (2015) Agent based energy management in railways. In: Proceedings of international conference on electrical systems for aircraft, railway, ship propulsion and road vehicles (ESARS), pp 1-6. doi:10.1109/ ESARS.2015.7101445

3. Sheu JW, Lin WS (2012) Energy-saving automatic train regulation using dual heuristic programming. IEEE Trans Veh Technol 61(4):1503-1514. doi:10.1109/TVT.2012.2187225

4. Wang W, Cheng M, Wang Y, Zhang B, Zhu Y, Ding S, Chen W (2014) A novel energy management strategy of onboard supercapacitor for subway applications with permanent-magnet traction system. IEEE Trans Veh Technol 63(6):2578-2588. doi:10. 1109/TVT.2013.2293707

5. Xu G, Li W, Xu K, Song Z (2011) An intelligent regenerative braking strategy for electric vehicles. Energies 4(9):1461-1477. doi:10.3390/en4091461

6. Gonzalez-Gil A, Palacin R, Batty P, Powell JP (2014) Energyefficient urban rail systems: strategies for an optimal management of regenerative braking energy. In: Proceedings of international conference transport research arena: transport solutions from research to deployment, pp 1-9

7. Domínguez M, Fernández-Cardador A, Cucala AP, Pecharromán RR (2012) Energy savings in metropolitan railway substations through regenerative energy recovery and optimal design of ATO speed profiles. IEEE Trans Autom Sci Eng 9(3):496-504. doi:10. 1109/TASE.2012.2201148
8. Miyatake M, Ko H (2010) Optimization of train speed profile for minimum energy consumption. IEEJ Trans Electr Electron Eng 5(3):263-269. doi:10.1002/tee.20528

9. Shen XJ, Chen S, Li G, Zhang Y (2013) Configure methodology of onboard supercapacitor array for recycling regenerative braking energy of URT vehicles. IEEE Trans Ind Appl 49(4):1678-1686. doi:10.1109/TIA.2013.2257976

10. Battistelli L, Ciccarelli F, Lauria D, Proto D (2009) Optimal design of DC electrified railway stationary storage system. In: Proceedings of international conference on clean electrical power, pp 739-745. doi:10.1109/ICCEP.2009.5211971

11. Jung B, Kim H, Kang H, Lee H (2014) Development of a novel charging algorithm for on-board ESS in DC train through weight modification. J Electr Eng Technol 9(6):1795-1804. doi:10.5370/ JEET.2014.9.6.1795

12. Iannuzzi D, Tricoli P (2010) Optimal control strategy of onboard supercapacitor storage system for light railway vehicles. In: Proceedings of IEEE international symposium on industrial electronics, pp 280-285. doi:10.1109/ISIE.2010.5637559

13. Grigans L, Latkovskis L (2010) Study of control strategies for energy storage system on board of urban electric vehicles. In: Proceedings of 14th international power electronics and motion control conference, pp T9-34-T9-38. doi:10.1109/EPEPEMC.2010.5606856

14. Xia H, Yang Z, Lin F, Chen H (2015) Modeling and state of charge-based energy management strategy of ultracapacitor energy storage system of urban rail transit. In: Proceedings of 41st annual conference of the IEEE industrial electronics society, pp 002083-002087. doi:10.1109/IECON.2015.7392408

15. Talla J, Streit L, Peroutka Z, Drabek P, Blahnik V (2015) Fuzzy energy management strategy for tram with supercapacitors. In: Proceedings of 41st annual conference of the ieee industrial electronics society, pp 003963-003968. doi:10.1109/IECON.2015.7392718

16. Sumpavakup C, Kulworawanichpong T (2015) Multi-train movement simulation using MATLAB object-oriented programming. Appl Mech Mater 763:153-158. doi:10.4028/www.scientific.net/AMM.763.153

17. Kulworawanichpong $\mathrm{T}$ (2004) Optimising AC electric railway power flows with power electronic control. Ph.D. Thesis, University of Birmingham, UK

18. Lu S (2011) Optimising power management strategies for railway traction. Ph.D. Thesis, University of Birmingham, UK

19. Nash A, Huerlimann D (2003) OPENTRACK-Simulation of railway networks, user manual version 1.3. Institute for Transportation Planning and Systems, ETH Zurich, Switzerland

20. Rochard BP, Schmid F (2000) A review of methods to measure and calculate train resistances. Proc IMechE Part F J Rail Rapid Transit 214(4):185-199. doi:10.1243/0954409001531306

21. Lee HM, Jeon EJ, Jeong SC (2010) A study on calculation of DC railway loadflow with energy storage system. In: Proceedings of international conference on control, automation and systems, pp 800-803. doi:10.1109/ICCAS.2010.5670179

22. Masamichi O (2010) Onboard storage in Japanese electrified lines. In: Proceedings of international conference power electronics and motion control, pp 9-16. doi:10.1109/EPEPEMC.2010.5606559

23. Vazquez S, Lukic SM, Galvan E, Franquelo LG, Carrasco JM (2011) Energy storage systems for transport and grid applications. IEEE Trans Ind Electron 57(12):3881-3895. doi:10.1109/TIE. 2010.2076414

24. Ratniyomchai T, Hillmansen S, Tricoli P (2014) Recent developments and applications of energy storage devices in electrified railways. IET Electr Syst Transp 4(1):9-20. doi:10.1049/iet-est. 2013.0031

25. Goldberg DE, Edward D (1989) Genetic algorithms in search, optimization and machine learning, 1st edn. Addison-Wesley, Massachusetts

26. Bombardier Inc. (2009) EcoActive Technology-MITRAC Energy Saver. datasheet, Zurich, Switzerland 